\title{
BMJ
}

\section{Universal parenting programme to prevent early childhood behavioural problems: cluster randomised trial}

\author{
Harriet Hiscock, postdoctoral research fellow and paediatrician, 1,2,3 Jordana K Bayer, postdoctoral research \\ fellow and clinical child psychologist, ,2,3 Anna Price, research assistant, ${ }^{1,3}$ Obioha C Ukoumunne, \\ postdoctoral research fellow and statistician, ${ }^{2,3,4}$ Susan Rogers, clinical research fellow, ${ }^{5}$ Melissa Wake, \\ paediatrician and senior research fellow $w^{1,2,3}$
}

${ }^{1}$ Centre for Community Child Health, Royal Children's Hospital, Parkville VIC 3052, Australia

${ }^{2}$ Department of Paediatrics, University of Melbourne, Parkville ${ }^{3}$ Murdoch Children's Research Institute, Parkville

${ }^{4}$ Clinical Epidemiology and Biostatistics Unit, Royal Children's Hospital, Parkville

${ }^{5}$ Parenting Research Centre, Carlton, VIC 3053

Correspondence to: $\mathrm{H}$ Hiscock harriet.hiscock@rch.org.au

doi:10.1136/bmi.39451.609676.AE

\section{ABSTRACT}

Objective To determine whether a parenting programme, offered universally in primary care, can prevent behavioural problems in children and improve parenting and maternal mental health.

Design Cluster randomised trial.

Setting 40 primary care nursing centres (clusters) in Victoria, Australia.

Participants 733 English speaking mothers of 8 month old children sequentially recruited from well child appointments; 656 retained at 24 months.

Intervention Structured three session programme at age 8-15 months, co-led by well child providers and a parenting expert. The programme covered normal development and behaviour, strategies to increase desired behaviour, and strategies to reduce unwanted behaviour.

Main outcome measures Maternal report of child externalising behaviour (child behavior checklist $1 \frac{1}{2}$ -5 year old), parenting (parent behavior checklist), and maternal mental health (depression anxiety stress scales) at 18 and 24 months.

Results At 18 months, child behaviour and parenting scores were similar in the two groups. At 24 months, externalising scores in the intervention and control groups were similar (mean 11.9 (SD 7.2) v 12.9 (7.4)); however, on the parent behavior checklist subscale scores, intervention group parents were less likely to report harsh/abusive parenting (mean 38.9 (SD 7.7) v 40.5 (8.8); adjusted mean difference $-1.83,95 \%$ confidence interval -3.12 to -0.55$)$ and unreasonable expectations of child development $(40.9$ (9.9) v 42.7 (9.6); $-2.18,-3.74$ to -0.62 ). Mean scores for nurturing parenting and maternal mental health were similar in the two groups at both times.

Conclusions A universal parenting programme resulted in modest improvement in parenting factors that predict behavioural problems in children but did not reduce externalising behavioural problems or affect maternal mental health at 2 years.

Trial registration ISRCTN 77531789.

\section{INTRODUCTION}

Behavioural problems affect approximately one in seven 4-17 year olds in Australia and internationally and have major personal, societal, and economic ramifications..$^{1-3}$ Behavioural problems in children are primarily grouped as externalising (such as oppositional defiance, aggression) and internalising (such as anxiety/depression, withdrawal) problems. $^{1}$ Left untreated, up to $50 \%$ of behavioural problems in preschool children develop into later mental health problems, including oppositional defiant disorder, conduct disorder, and depression. ${ }^{4}$ In addition to the substantial costs of treating such problems, social costs include increased school dropout and subsequent unemployment, family stress and break down, increased drug and alcohol misuse, and increased crime. $^{2}$

Possible approaches to reducing childhood mental health problems include management of established problems, secondary prevention targeting children with either family/social risk factors or early signs of disorder, and universal prevention offered to all children. ${ }^{5}$ Management approaches include drug treatment, individual psychotherapy, and parenting programmes, the last of which have the strongest evidence of efficacy to date. ${ }^{26-8}$ Parenting programmes share the goals of modifying the key aspects of parenting known to contribute to behavioural problems in children, by reducing harsh or abusive parenting, increasing warm parenting, and informing parental knowledge of normal development. ${ }^{2679}$ Although effective, parenting programmes are costly and time intensive, require an available workforce trained in delivery of evidence based treatments, and are currently accessible to few children. ${ }^{1}$ Given that treatment services can never hope to meet the needs of all children with mental health problems, prevention is an essential first step in a public health approach that would also include adequate treatment services. ${ }^{10}$

Several high quality randomised trials have now reported on targeted approaches for high risk families. Substantial effect sizes have been reported for approaches targeting children with early behavioural 
problems: $0.3-0.7$ for reductions in parenting risks and 0.5-0.9 for reductions in behavioural problems. ${ }^{11-13}$ Approaches targeting children with family or social risk factors also seem to be effective but have targeted very restricted populations (very disadvantaged young mothers, families eligible for food assistance, and socioeconomically disadvantaged areas). ${ }^{114-18}$

However, all targeted approaches share five possible limitations: misclassification of children on the basis of early risk factors, as at most half of the children who later develop mental health problems have identifiable risk factors and are therefore likely to be targeted by such programmes ${ }^{1019}$; stigmatisation, which can lead to poor uptake rates ${ }^{20}$; delivery to only the minority at highest risk, when most children with subsequent mental health problems come from the numerically much larger "low risk" population ${ }^{10}$; lack of denominator figures in published studies that are critical to enable estimation of population risk reduction and thus determination of impact at the population level; and a tendency to offer targeted programmes to children of preschool or primary school age, by which time their behaviour may already have had substantial and lasting negative effects.

Universal prevention offered to all families lacks these limitations. ${ }^{5}$ However, no high quality evidence showing the effectiveness of universal prevention has been published. ${ }^{26}$ Here, we report intermediate trial outcomes of the first truly universal parenting programme aiming to prevent early childhood externalising behaviours before onset. As previously reported, ${ }^{21}$ programme content was informed by a review of the literature on intervention (social learning and attachment theoretical perspectives) and developed in partnership with parenting experts and well child providers. We designed the programme to be suitable for all parents and to be delivered by trained health professionals working in the primary care setting. We hypothesised that families receiving the intervention would report fewer childhood externalising behavioural problems; less harsh discipline, more nurturing parenting, and more reasonable expectations of normal child development; and fewer symptoms of maternal depression or anxiety. We powered the study to be able to detect much smaller effect sizes than those reported for targeted approaches, given that the entire population is the denominator.

\section{METHODS}

\section{Setting and participants}

We ran the trial in greater Melbourne (population 3.4 million), Victoria, Australia. We ranked Melbourne's 31 local government areas by the census derived socioeconomic indexes for areas index of relative disadvantage ${ }^{22}$; we then divided them into thirds representing low, middle, and high socioeconomic status. From each third, we selected two local government areas to provide a broad spread of social circumstance; all maternal and child health nurses in these six local government areas participated.
In Victoria, free health visits are scheduled at 1, 2, 4, $6-8,12,18,24$, and 42 months of age, and more than $90 \%$ of all parents attend visits during the first six months. ${ }^{23}$ To access a key developmental transition associated with an abrupt rise in parenting challenges (that is, the point at which infants become mobile), maternal and child health nurses consecutively invited mothers of 6-7 month old infants attending in August/ September 2004 to take part in the toddlers without tears study. Mothers with insufficient English to complete questionnaires were excluded. The research team telephoned interested mothers and mailed the baseline questionnaire to be returned with written informed consent.

\section{Universal intervention}

The intervention consisted of three sessions targeting key modifiable parenting risk factors for childhood behavioural problems: unreasonable expectations, harsh parenting, and lack of nurturing parenting. ${ }^{279}$ At the routine 8 month visit, mothers received four handouts discussing normal child behavioural, motor, and social development over the ensuing 12 months and ways to encourage language development. At 12 months, parents attended a two hour group session discussing ways to develop a warm and sensitive relationship with their toddler and to plan for and encourage desirable behaviour in toddlers. The session introduced the need to plan ahead for "difficult" situations in which toddlers are likely to misbehave and offered alternatives to common "irrational beliefs" by parents that can lead to harsh parenting. At 15 months, parents attended another two hour group session discussing ways to manage unwanted behaviour in children. Rather than smacking and yelling, parents were encouraged to identify "low priority" problem behaviours (for which strategies such as planned ignoring, distraction, and logical choices were discussed) and "high priority" behaviours (for which "quiet time" was discussed). All sessions took place at a local maternal and child health centre and were delivered by a nurse and a co-facilitator expert in running parenting groups. Programme content drew on attachment theory (warm, sensitive parent-child interactions) and social learning theory (reinforcing desired behaviours and extinguishing undesirable behaviours).

Intervention nurses attended a half hour training session (for the 8 month session) and two 2.5 hour training sessions (for the 12 and 15 month sessions) led by $\mathrm{HH}$ (paediatrician) and JB (child psychologist) and underpinned by a programme manual and written handouts for parents. Training incorporated didactic teaching, written information, role play, and video vignettes of appropriate parenting responses to common childhood behaviours. The standardised programme manual and training encouraged fidelity to the programme, and nurses completed a checklist at the end of each group session to record components of the intervention delivered. 


\section{Usual care}

Families in the control arm received usual care from their maternal and child health centre, which may include advice on children's behaviour but does not include a structured, evidence based parenting programme for early childhood behaviour.

\section{Measures}

Mothers completed written questionnaires at 7 months (baseline sociodemographic details, maternal mental health, and family stress), 12 months (baseline parenting style and partner relationship), and 18 and 24 months (outcomes). The primary outcome was externalising behavioural problems measured with the 99 item validated child behavior checklist $1 \frac{1}{2}-5$ year old. ${ }^{24}$ The checklist also quantifies internalising behavioural problems and yields both raw scores (used in this report to compare groups as our primary outcome) and $\mathrm{T}$ scores with a clinical cut point derived from the

Eligible births ( $n=1069,52 \%$ male)

Contacted for 6-7 month maternal and child health visit across six local government areas
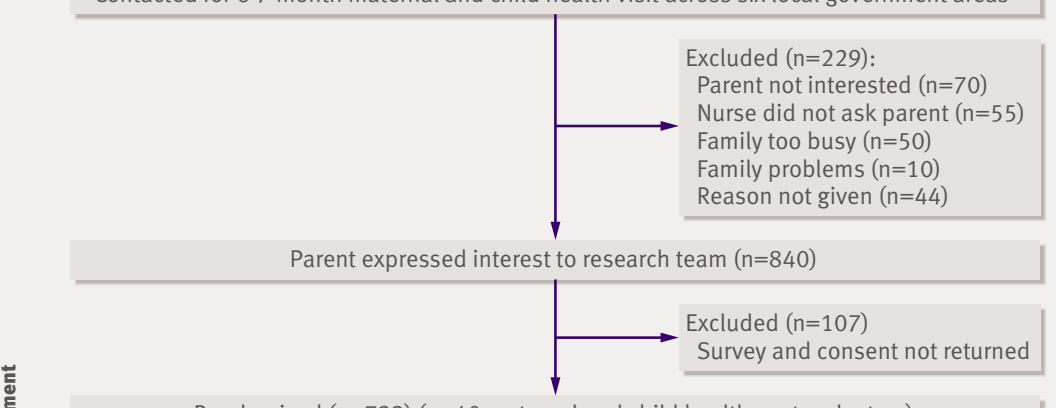

Randomised $(n=733)$ ( $n=40$ maternal and child health centre clusters)

\begin{tabular}{|c|}
\hline $\begin{array}{l}\text { Allocated to intervention ( } \mathrm{n}=329 \text { families) } \\
\text { (n=18 maternal and child health centre } \\
\text { clusters; average cluster size } 18 \text { families, } \\
\text { range } 6-33)\end{array}$ \\
\hline $\begin{array}{l}\text { Received parent handouts ( } n=323 \text { families) } \\
\text { Attended } 8 \text { month visit* }(n=307 \text { families) } \\
\text { Attended } 12 \text { month group* }(n=222 \text { families) } \\
\text { Attended } 15 \text { month group* }(n=185 \text { families) } \\
\text { Received no part of intervention }(n=6)\end{array}$ \\
\hline$\downarrow$ \\
\hline $\begin{array}{l}\text { Lost to follow-up (12 months) } \dagger \\
\qquad(\mathrm{n}=15 \text { families })\end{array}$ \\
\hline \multirow[b]{2}{*}{$\begin{array}{l}\text { Lost to follow-up (18 months) } \dagger \\
\qquad(\mathrm{n}=31 \text { families })\end{array}$} \\
\hline \\
\hline \multirow{2}{*}{$\begin{array}{l}\text { Lost to follow-up (24 months)† } \\
(\mathrm{n}=37 \text { families })\end{array}$} \\
\hline \\
\hline$\downarrow$ \\
\hline $\begin{array}{l}\text { Analysed } \\
\text { At } 18 \text { months ( } n=298 \text { families, } 90.6 \% \text { ) } \\
\text { At } 24 \text { months ( } n=292 \text { families, } 88.8 \% \text { ) }\end{array}$ \\
\hline $\begin{array}{l}\text { Excluded from analysis } \\
\text { Did not return either } 18 \text { or } 24 \text { month } \\
\text { follow-up questionnaire ( } n=5 \text { families) }\end{array}$ \\
\hline
\end{tabular}

1

Allocated to control ( $n=404$ families) $(n=22$ maternal and child health centre clusters; average cluster size 18 families, range $7-84$ )

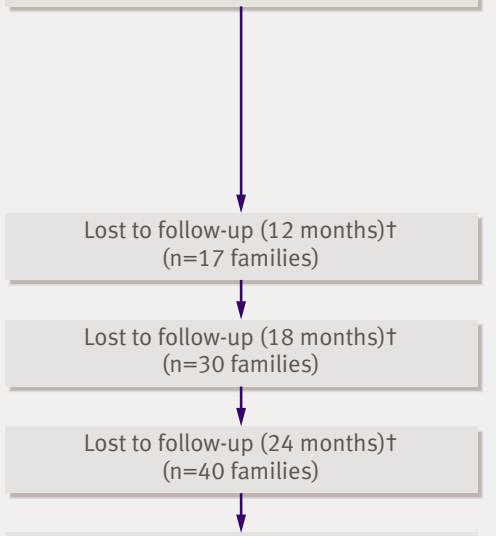

Analysed

At 18 months ( $n=374$ families, $95.6 \%$ )

At 24 months ( $n=364$ families, $90.1 \%$ )

Excluded from analysis

Did not return either 18 or 24 month follow-up questionnaire ( $n=1$ family) combined norming sample of children aged 1-5 years (used in this report to describe our sample relative to international norms). Another validated outcome measure was the parent behavior checklist, ${ }^{9}$ a 32 item measure of three parenting styles known to contribute to childhood behavioural problems (harsh discipline, nurturing parenting, and expectations of normal development) for parents of preschool (1-5 years) children. The parent behavior checklist yields T scores (mean 50, SD 10) derived from norms with 6 month age bands but no clinical cut points. We measured maternal mental health with the depression anxiety stress scales, ${ }^{25}$ a 21 item measure that, as well as mean scores for each subscale, has cut points to indicate risk of depression (score $>9$ ), anxiety (score $>7$ ), and stress (score $>14$ ). We measured children's temperament, a potential confounder of the effect of the parenting programme, with a parent rated global temperament item $(1=$ "much easier than average" to $5=$ "much more difficult than average"). ${ }^{26}$ Sociodemographic factors included infants' sex and birth order, maternal age, marital status, education, and language mainly spoken at home. We assigned each family an Australian index of disadvantage score based on the postal code of their home address (72 separate postcodes in the six local government areas, index of disadvantage mean 1044.5, SD 68.9, range 825-1140)..$^{22}$

\section{Randomisation}

We ran the trial in accordance with the CONSORT statement for cluster randomised trials. ${ }^{27} \mathrm{We}$ randomised maternal and child health centres (clusters) in the study to minimise the contamination that could occur when participants attending the same centre are randomised to different groups. After recruitment was complete, an independent statistician randomly allocated maternal and child health centres (and therefore their families), stratified by local government area, to intervention or control arms. Within each of the local government areas, a list of participating centres was created. As we considered balance on socioeconomic status to be important, randomisation was done with a computer generated allocation sequence by matching pairs of centres according to the closeness of their average socioeconomic disadvantage scores and then randomising one centre from each pair to the intervention arm. Masking occurred at randomisation, with group allocation concealed from researchers and participants until allocation was complete.

\section{Sample size}

To detect a reduction of 0.3 standard deviation units in the mean score for the primary outcomes with $80 \%$ power at the two sided significance level of $0.05,175$ children would be needed for each of the intervention and control groups. We inflated this sample size by a design effect of 1.18 to 210 infants per trial arm to allow for correlation between responses within the same cluster (that is, maternal and child health centre), ${ }^{28}$ assuming an average cluster size of seven (the number 
of eligible mothers attending each centre) and an intracluster correlation coefficient of 0.03. Assuming a $30 \%$ dropout rate, the study needed a final sample size of 300 infants in each trial arm.

\section{Analyses}

We analysed the trial arms as randomised at the level of the individual, applying the intention to treat principle. We implemented unadjusted and adjusted analyses (potential prognostic factors listed in table 2) of the outcomes (all quantitative) by using random effects linear regression models fitted by maximum likelihood estimation to allow for the correlation between the responses of participants from the same maternal and child health centre. ${ }^{29} \mathrm{We}$ present means and standard deviations for each trial arm, along with the mean difference between arms, 95\% confidence intervals, and $\mathrm{P}$ values. We calculated effect sizes by dividing the mean difference between the trial arms by the pooled standard deviation. We used the bootstrap method to validate analyses of all skewed outcomes. ${ }^{30} \mathrm{We}$ used Stata 9.2 for the analyses.

\section{RESULTS}

Of the 1069 eligible families, 840 expressed interest and $733(69 \%)$ completed the baseline questionnaire

Table 1|Baseline characteristics by trial arm. Values are numbers (percentages) unless stated otherwise

\begin{tabular}{|c|c|c|}
\hline Variable & Intervention group $(n=329)$ & Control group $(n=404)$ \\
\hline \multicolumn{3}{|l|}{ Children } \\
\hline Girls & $164(49.8)$ & $193(47.8)$ \\
\hline First born & $184 / 328(56.1)$ & $206 / 403(51.1)$ \\
\hline "Difficult" temperament* & $17 / 322(5.3)$ & $27 / 395(6.8)$ \\
\hline \multicolumn{3}{|l|}{ Mothers } \\
\hline Mean (SD) age (years) & $33.0(4.8)(n=328)$ & $33.3(4.7)(n=401)$ \\
\hline Married or cohabitating & $318(96.7)$ & $390(96.5)$ \\
\hline Currently working & $82 / 328(25.0)$ & $120(29.7)$ \\
\hline English spoken at home & $317(96.4)$ & $387(95.8)$ \\
\hline Highest level of education: & $(n=328)$ & \\
\hline Did not complete high school & $65(19.8)$ & $85(21.0)$ \\
\hline Completed high school & $113(34.5)$ & $130(32.2)$ \\
\hline $\begin{array}{l}\text { Completed tertiary/postgraduate } \\
\text { degree }\end{array}$ & $150(45.7)$ & $189(46.8)$ \\
\hline \multicolumn{3}{|l|}{ Mental health: } \\
\hline Mean (SD) depression score & $4.1(5.4)$ & $3.5(4.5)(n=403)$ \\
\hline Depressed & $46(14.0)$ & $37 / 403(9.2)$ \\
\hline Mean (SD) anxiety score & $2.2(3.6)(n=328)$ & $1.9(3.1)(n=402)$ \\
\hline Anxious & $32 / 328(9.8)$ & $27 / 402(6.7)$ \\
\hline Mean (SD) stress score & $9.0(6.5)$ & $8.8(6.3)(n=403)$ \\
\hline Stressed & $46(14.0)$ & $50 / 403(12.4)$ \\
\hline \multicolumn{3}{|l|}{ Family } \\
\hline Household income per annum (\$AUS): & $(n=297)$ & $(n=389)$ \\
\hline$\ll 30000$ & $27(9.1)$ & $41(10.5)$ \\
\hline $30000-60000$ & $95(32.0)$ & $129(33.2)$ \\
\hline$>60000$ & $175(58.9)$ & $219(56.3)$ \\
\hline $\begin{array}{l}\text { Mean (SD) socioeconomic } \\
\text { disadvantage score }\end{array}$ & $1046(67)(n=325)$ & $1043(70)(n=401)$ \\
\hline
\end{tabular}

*Parent rated child as more difficult than average. (figure). Non-participating families were more likely than participating families to have low index of disadvantage scores (mean 1033.7 (SD 74.6), range 825-1132, $\mathrm{P}=0.03$ ), but sex of child was similar in participating and non-participating families. Table 1 describes characteristics of the sample. At 18 months, $299(91 \%)$ intervention families and $373(92 \%)$ control families returned their questionnaires; this fell to 293 $(89 \%)$ and $363(90 \%)$ at 24 months. All families returned at least one questionnaire. Families who completed the follow-up questionnaires were representative of the baseline sample with respect to sex and temperament of children, maternal education and mental health, and household income and index of disadvantage score.

\section{Programme fidelity}

Content checklists completed by nurses indicated that the full programme was delivered for $95 \%$ of group sessions. In the intervention arm, 307 (93\%) families attended the 8 month visit, $222(67 \%)$ families attended a 12 month group, $185(56 \%)$ attended a 15 month group, and 160 (49\%) attended both groups. Primary reasons offered when parents missed group sessions were "family member sick" (52 families), "too busy" (28 families), and "no childcare" (27 families). On average, the number of parents at each group session was seven (range 2-12). The research team mailed the written handouts to all intervention families who missed groups at the maternal and child health centres, $98 \%$ of whom subsequently reported receiving the handouts.

\section{Childhood behaviour}

Compared with US externalising $\mathrm{T}$ score norms for 1-5 year olds (mean 50 (SD 10); 10\% above clinical cut point), our sample of toddlers had slightly lower externalising problems at 18 months (mean 49.0 (SD $8.9) ; 4.5 \%$ above clinical cut point) and 24 months (49.5 $(9.4) ; 6 \%)$. Internalising problems were also lower.

The mean (raw) externalising behaviour scores were similar in the intervention and control groups at 18 months (mean 12.1 (SD 6.9) v 11.9 (6.8); adjusted mean difference $0.16,95 \%$ confidence interval -1.01 to 1.33; $\mathrm{P}=0.79$ ) and 24 months (mean $11.9(\mathrm{SD} 7.2)$ v 12.9 (7.4); adjusted mean difference $-0.79,-2.27$ to 0.69 ; $\mathrm{P}=0.30)$. Mean internalising scores were also similar in the two groups at both 18 and 24 months (table 2).

\section{Parenting}

At 18 months, mean harsh discipline and unreasonable developmental expectations scores were similar in intervention families and control families. By 24 months, intervention mothers reported less harsh discipline and unreasonable expectations with their toddlers than did control mothers. For the harsh discipline subscale, the adjusted mean difference of $-1.83(95 \%$ confidence interval -3.12 to -0.55 ; $\mathrm{P}=0.005)$ corresponds to an effect size of $-0.22(95 \%$ confidence interval -0.38 to -0.07$)$. For the 
Table 2 | Main outcome comparisons

\begin{tabular}{|c|c|c|c|c|c|c|c|}
\hline \multirow[b]{2}{*}{ Outcome } & \multicolumn{2}{|c|}{ Intervention arm (I) } & \multicolumn{2}{|c|}{ Control arm (C) } & \multirow{2}{*}{$\begin{array}{l}\text { Unadjusted mean } \\
\text { difference }\end{array}$} & \multicolumn{2}{|c|}{ Adjusted mean difference (I minus C) } \\
\hline & Mean (SD) & No & Mean (SD) & No & & Estimate $(95 \% \mathrm{Cl})$ & $P$ value \\
\hline \multicolumn{8}{|l|}{18 months } \\
\hline \multicolumn{8}{|l|}{ Childhood behaviour: } \\
\hline Externalising score & $12.1(6.9)$ & 295 & $11.9(6.8)$ & 373 & 0.21 & $0.16(-1.01$ to 1.33$)$ & 0.79 \\
\hline Internalising score & $6.0(4.2)$ & 295 & $5.6(4.3)$ & 373 & 0.40 & $0.49(-0.20$ to 1.18$)$ & 0.16 \\
\hline \multicolumn{8}{|l|}{ Parenting: } \\
\hline Unreasonable expectations & $41.6(10.4)$ & 297 & $43.0(10.3)$ & 373 & -1.43 & $-1.58(-3.21$ to 0.05$)$ & 0.06 \\
\hline Warm nurturing & $55.4(9.3)$ & 298 & $54.8(9.8)$ & 373 & 0.43 & $0.42(-1.22$ to 2.06$)$ & 0.62 \\
\hline Harsh discipline & $42.4(5.3)$ & 298 & $42.9(5.4)$ & 373 & -0.50 & $-0.72(-1.54$ to 0.10$)$ & 0.08 \\
\hline \multicolumn{8}{|l|}{ Maternal mental health: } \\
\hline Depression & $3.4(4.3)$ & 296 & $2.9(4.3)$ & 373 & 0.43 & 0.34 (-0.31 to 0.99$)$ & 0.30 \\
\hline Anxiety & $1.9(3.4)$ & 297 & $1.8(3.1)$ & 373 & 0.11 & $0.12(-0.37$ to 0.61$)$ & 0.64 \\
\hline Stress & $8.2(5.7)$ & 298 & $7.7(6.1)$ & 373 & 0.47 & $0.26(-0.63$ to 1.14$)$ & 0.57 \\
\hline
\end{tabular}

\section{4 months}

Childhood behaviour:

\begin{tabular}{|c|c|c|c|c|c|c|c|}
\hline Externalising score & $11.9(7.2)$ & 292 & $12.9(7.4)$ & 362 & -0.97 & $-0.79(-2.27$ to 0.69$)$ & 0.30 \\
\hline Internalising score & $6.4(6.1)$ & 292 & $6.4(6.0)$ & 362 & -0.02 & $0.19(-0.77$ to 1.15$)$ & 0.70 \\
\hline \multicolumn{8}{|l|}{ Parenting: } \\
\hline Unreasonable expectations & $40.9(9.9)$ & 291 & $42.7(9.6)$ & 363 & -2.03 & $-2.18(-3.74$ to -0.62$)$ & 0.006 \\
\hline Warm nurturing & $53.5(11.3)$ & 291 & $53.7(11.2)$ & 363 & -0.54 & $-0.67(-2.75$ to 1.41$)$ & 0.53 \\
\hline Harsh discipline & $38.9(7.7)$ & 291 & $40.5(8.8)$ & 363 & -1.66 & $-1.83(-3.12$ to -0.55$)$ & 0.005 \\
\hline \multicolumn{8}{|l|}{ Maternal mental health: } \\
\hline Depression & $3.5(5.2)$ & 291 & $2.9(4.0)$ & 363 & 0.64 & $0.67(-0.11$ to 1.45$)$ & 0.09 \\
\hline Anxiety & $2.0(3.9)$ & 291 & $1.9(3.4)$ & 363 & 0.06 & $0.08(-0.58$ to 0.73$)$ & 0.82 \\
\hline Stress & $8.6(6.3)$ & 291 & $8.3(5.9)$ & 363 & 0.26 & $0.09(-1.04$ to 1.23$)$ & 0.87 \\
\hline
\end{tabular}

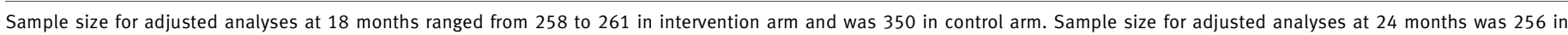

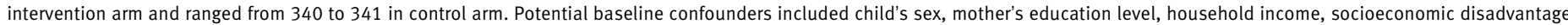
score, child's temperament status, and whether mother was depressed, anxious, or stressed.

unreasonable developmental expectations subscale, the adjusted mean difference of -2.18 ( -3.74 to -0.62 ; $\mathrm{P}=0.006)$ corresponds to an effect size of $-0.22(-0.38$ to $-0.06)$. Mean scores for nurturing parenting were similar in the two groups at both 18 and 24 months (table 2).

\section{Maternal mental health}

The mean maternal depression, anxiety, and stress subscale scores were not markedly different between the two groups at either 18 or 24 months (table 2).

\section{DISCUSSION}

A universal parenting programme, designed to prevent early childhood behavioural problems, resulted in modest reductions in maternal report at 24 months of parenting risk factors known to predict such problems. ${ }^{2679}$ Although the intervention reduced harsh parental discipline and inappropriate developmental expectations, it did not lead to more nurturing parenting (which was high in both groups). The programme was acceptable to parents, was feasible in a routine primary care setting, and achieved greater reach than other reported programmes. However, we showed no significant impact on externalising behavioural problems in 2 year olds or on maternal mental health.

\section{Strengths}

The study had several strengths. Firstly, a 69\% uptake on the basis of eligible birth records is high for population trials. ${ }^{5}$ Non-participants' index of disadvantage scores were only marginally lower than those of participants, indicating that our results could be generalised to a wide socioeconomic spectrum, although perhaps not the lowest end. Secondly, we used well validated parent reported outcome measures appropriate to this age group. Thirdly, all clusters and more than $85 \%$ of all families remained in the trial, strongly supporting both the validity of the findings and the acceptability of the approach.

\section{Limitations}

We included single source (maternal report) rather than multi-source assessment, and the results could thus be open to bias as mothers could not be blinded to their group membership. Although primary caregiver report is recognised as the most useful measure of early childhood behaviour, ${ }^{31}$ multi-source assessment, including paternal report, could assess the family environment and childhood behavioural outcomes more extensively. However, direct observational measures are generally impractical for population based studies of this size, ${ }^{32}$ and, because many children are not yet attending out of home care on a regular 


\section{WHAT IS ALREADY KNOWN ON THIS TOPIC}

Behavioural problems affect up to $20 \%$ of children and have cumulative personal, societal, and economic ramifications

Prevention targeted to high risk families can be effective but has limited population reach and may stigmatise recipients

\section{WHAT THIS STUDY ADDS}

By age 24 months, a brief, universally offered parenting programme led to modest improvements in parenting risks known to contribute to child behavioural problems but did not improve maternal distress or toddlers' behaviour

Longer term follow-up is needed to determine effectiveness in preventing preschool behavioural problems universal programme to prevent behavioural problems in toddlers. If additional, longer term benefits emerge by preschool age, such universal prevention could be considered as a component of population childhood mental health strategies, in conjunction with effective targeted prevention and clinical treatment programmes.

We thank maternal and child health nurses and families of the Melbourne cities of Glen Eira, Greater Geelong, Kingston, Maribyrnong, Nillumbik, and Stonnington who took part in this research and the co-facilitators from the Parenting Research Centre.

Contributors: $\mathrm{HH}, \mathrm{JKB}$, and $\mathrm{MW}$ were involved in the conception and design of the study and obtained funding. $\mathrm{HH}, \mathrm{JKB}, \mathrm{SR}$, and AP were involved with acquisition of study data and, together with OCU and MW, were responsible for analysis and interpretation of the data. OCU did the statistical analysis with assistance from AP. HH and JKB drafted the manuscript with critical revision from OCU, MW, AP, and SR. HH is the guarantor.

Funding: This project was funded by the Telstra Community Development Fund. The authors' work was independent of the funders. HH's and OCU's postdoctoral positions are funded by Australian National Health and Medical Research Council (NHMRC) Population Health Capacity Building Grant 436914; MW is part funded by NHMRC Career Development Award 284556; and JB is part funded by an Australian Rotary Health Research Fund Postdoctoral Fellowship.

Competing interests: None declared.

Ethical approval: Ethics in Human Research Committee of the Royal Children's Hospital, Melbourne, Australia (project approval 24020A).

$31 \%$ of eligible families who did not join the trial were hard to reach, high risk families as opposed to capable, experienced families who rightly saw no need for the programme. Nevertheless, we successfully recruited many families with known risk factors for behavioural problems; $39 \%$ of the final sample were exposed to clinical levels of maternal depression, anxiety, and stress symptoms; substance misuse; partner conflict; social isolation; or financial problems. ${ }^{5}$

Thirdly, although almost all families received some of the programme, only $49 \%$ received the full programme, underscoring the difficulty of implementing a true population prevention programme. If the parenting programme became part of routine primary care, the dosage received by families could conceivably increase (owing to streamlining and promotion of local sessions) but equally could further decrease. Fourthly, we report here only short term outcomes, but interventions for externalising behaviour may have "sleeper" effects, ${ }^{33}$ the detection of which would require longer term follow-up. ${ }^{33}$

\section{Meaning of the study}

This is the first trial to evaluate a parenting programme delivered with a truly universal, as opposed to high risk, sample involving the full spectrum of social advantage through disadvantage. Previous prevention trials targeting existing behavioural problems reported parenting effect sizes ranging from 0.3 to 0.7 . Our effect size on parenting behaviours of 0.2 , although modest, is therefore promising, given the brevity of this universal prevention programme that started in infancy before the onset of any behavioural difficulties. However, this would only be of value if flow-on effects were shown at a population level at 3 years or beyond.

In conclusion, the outcomes at 2 years are insufficient to support widespread introduction of a very early

1 Sawyer MG, Arney FM, Baghurst PA, Clark JJ, Graetz BW, Kosky RI, et al. The mental health of young people in Australia . Canberra ACT: Mental Health and Special Programs Branch, Commonwealth Department of Health and Aged Care, 2000.

2 Barlow I, Stewart-Brown S. Behaviour problems and group-based parent education programs. J Dev Behav Pediatr 2000;21:356-70.

3 Bor W, Najman JM, O'Callaghan GM, Williams GM, Anstey K. Aggression and the development of delinquent behaviour in children Canberra, ACT: Australian Institute of Criminology, 2001. (Trends and issues in crime and criminal justice series, No 201.)

4 Campbell S. Behavior problems in preschool children: a review of recent research. J Child Psychol Psychiatry 1995;36:113-49.

5 Bayer JK, Hiscock H, Morton-Allen E, Ukoumunne OU, Wake M. Prevention of mental health problems: rationale for a universal approach. Arch Dis Child 2007;92:34-8.

6 Barlow J, Parsons J, Stewart-Brown S. Preventing emotional and behavioural problems: the effectiveness of parenting programmes for children less than three years of age. Child Care Health Dev 2005;31:33-42.

7 Sanders MR, Gooley S, Nicholson I. Early intervention in conduct problems in children. Adelaide, SA: Australian Early Intervention Network for Mental Health in Young People, 2000.

8 Carr A. What works for children and adolescents? A critical review of psychological interventions with children, adolescents and their families . London: Routledge, 2000.

9 Brenner V, Fox RA. Parental discipline and behaviour problems in young children. J Genet Psychol 1998;159:251-6.

10 Offord DR, Chmura Kraemer H, Kazdin AE, Jensen PS, Harrington R. Lowering the burden of suffering from child psychiatric disorder: trade-offs among clinical, targeted, and universal interventions. J Am Acad Child Adolesc Psychiatry 1998;37:686-94.

11 Shaw DS, Dishion TJ, Supplee LH, Gardner F, Arnds K. Randomised trial of a family-centered approach to the prevention of early conduct problems: 2-year effects of the family check-up in early childhood. Consult Clin Psychol 2006;74:1-9.

12 Hutchings H, Gardner F, Bywater T, Daley D, Whitaker C, Jones K, et al. Parenting intervention in Sure Start services for children at risk of developing conduct disorder: pragmatic randomised controlled trial. BMJ 2007;334:678.

13 Morowska A, Sanders MR. Self-administered behavioral family intervention for parents of toddlers. Part 1: efficacy. J Consult Clin Psychol 2006;74:10-9.

14 Olds D, Henderson CR, Cole R, Eckenrode J, Kitzman H, Luckey D, et al. Long-term effects of nurse home visitation on children's criminal and antisocial behaviour: 15-year follow-up of a randomised controlled trial. JAMA 1998;280:1238-44.

15 Zubrick SR, Ward KA, Silburn SR, Lawrence D, Williams AA, Blair EM, et al. Prevention of child behaviour problems through universal 
implementation of a group behavioural family intervention. Prev $\mathrm{Sci}$ 2005;6:287-304.

16 Love JM, Kisker EE, Ross C, Raikes H, Constantine J, Boller K, et al. The effectiveness of early head start for 3-year-old children and their parents: lessons for policy and programs. Dev Psychol 2005;41:885-901.

17 Fergusson DM, Grant H, Horwood LJ, Ridder EM. Randomised trial of the early start program of home visitation. Pediatrics 2005;116:803-9.

18 Fergusson DM, Grant H, Horwood LJ, Ridder EM. Randomized trial of the early start program of home visitation: parent and family outcomes. Pediatrics 2006;117:781-6.

19 Bennett KJ, Lipman EL, Racine Y, Offord DR. Annotation: do measures of externalising behaviour in normal populations predict later outcome? Implications for targeted interventions to prevent conduct disorder. J Child Psychol Psychiatry 1998;39:1059-70.

20 Stewart-Brown S. Public health implications of childhood behaviour problems and parenting programmes. In: Buchanan A, Hudson B, eds. Parenting, schooling and children's behaviour . Sydney, NSW: Ashgate Press, 1998:21-33.

21 Hiscock H, Bayer JK, Wake M. Preventing toddler externalising behaviour problems: pilot evaluation of a universal parenting program. International Journal of Mental Health Promotion 2005;7:54-60.

22 Australian Bureau of Statistics, Commonwealth of Australia. Socioeconomic indexes for areas . Canberra ACT: ABS, 2001

23 Department of Human Services. Maternal and child health annual data report 2002-2003. Melbourne, Victoria: State Government of Victoria, 2005.
24 Achenbach T, Rescorla L. Child behavior checklist for ages 1 1/2 - 5 . Burlington VT: Achenbach System of Empirically Based Assessment, University of Vermont, 2000.

25 Lovibond PF, Lovibond SH. The structure of negative emotional states: comparison of the depression anxiety stress scales (DASS) with the Beck depression and anxiety inventories. Behav Res Ther 1995;33:335-43.

26 Sanson A, Oberklaid F, Pedlow R, Prior M. Risk indicators: assessment of infancy predictors of pre-school behavioural maladjustment.JChild Psychol Psychiatry 1991;32:609-26.

27 Campbell MK, Elbourne DR, Altman DG. CONSORT statement: extension to cluster randomised trials. BMJ 2004;328:702-8.

28 Donner A, Klar N. Design and analysis of cluster randomization trials in health research . London: Arnold, 2000.

29 Goldstein H. Multilevel statistical models . London: Arnold, 1995.

30 Davison AC, Hinkley DV. Bootstrap methods and their application . Cambridge: Cambridge University Press, 1997.

31 Glascoe FP. Screening for developmental and behavioral problems. Ment Retard Dev Disabil Res Rev 2005;11:173-9.

32 Heinrichs N, Bertram H, Kuschel A, Hahlweg K. Parent recruitment and retention in a universal prevention program for child behavior and emotional problems: barriers to research and program participation. Prev Sci 2005;6:275-86.

33 Tremblay RE, Nagin DS, Seguin JR, Zoccolillo MZ, Zelazo PD, Boivin MB, et al. Physical aggression during early childhood: trajectories and predictors. Pediatrics 2004;114:43-50.

Accepted: 21 November 2007 